\title{
Evolution of the Oil Shale Permeability under Real-Time High- Temperature Triaxial Stress in the Jimusar Area, Xinjiang
}

\author{
Lusheng Yang $\mathbb{D}^{1}$ and Peng $\mathrm{Li} \mathbb{D}^{2}$ \\ ${ }^{1}$ College of Basic Courses, Shanxi Institute of Energy, Jinzhong 030600, China \\ ${ }^{2}$ Department of Mining Engineering, Shanxi Institute of Energy, Jinzhong 030600, China
}

Correspondence should be addressed to Peng Li; lipeng@sxie.edu.cn

Received 24 September 2021; Accepted 8 November 2021; Published 24 November 2021

Academic Editor: Afshin Davarpanah

Copyright (C) 2021 Lusheng Yang and Peng Li. This is an open access article distributed under the Creative Commons Attribution License, which permits unrestricted use, distribution, and reproduction in any medium, provided the original work is properly cited.

\begin{abstract}
This paper adopts a real-time high-temperature triaxial seepage test system to study the permeability evolution of oil shale in the Jimusar area, Xinjiang, with the temperature, pore pressure, and volumetric stress. The results indicate that (1) the variation process of the oil shale permeability with the temperature can be divided into three stages: slow growth stage from 20 to $350^{\circ} \mathrm{C}$, rapid growth stage from 350 to $500^{\circ} \mathrm{C}$ with a threshold temperature of $400^{\circ} \mathrm{C}$, and growth deceleration stage from 500 to $600^{\circ} \mathrm{C}$. (2) With increasing pore pressure, the permeability gradually decreases. Under a volumetric stress of $17 \mathrm{MPa}$, the permeability decreases the most rapidly from 1 to $2 \mathrm{MPa}$, and under a volumetric stress of $34 \mathrm{MPa}$, the permeability decreases the fastest from 1 to $3 \mathrm{MPa}$. (3) The oil shale permeability decreases with increasing volumetric stress. At room temperature, the decrease magnitude of the permeability is small and increases with increasing temperature. The results can provide a theoretical reference for the analysis of the seepage process of thermal fluids and pyrolysis oil and gas in oil shale.
\end{abstract}

\section{Introduction}

Oil shale is a kind of sedimentary rock containing organic matter (kerogen) with a low permeability. After heating, kerogen can be converted into shale oil and gas and can be used as fuel and chemical raw materials. The proven oil shale reserves in China reach approximately 719.9 billion tons, which can be converted into 47.6 billion tons of shale oil [1-3], which is much higher than the recoverable oil resources of 26.8 billion tons. Oil shale is mainly located in Liaoning, Jilin, Xinjiang, Guangdong, and other areas [4]. As a very large proportion of unconventional oil and gas resources, the efficient and green development and utilization of oil shale could be of great importance to improve the energy security in China and the strategic reserves of oil and gas resources.

The utilization of oil shale can be divided into two types: ground dry distillation furnace pyrolysis and in situ thermal injection pyrolysis. Among these methods, ground dry distillation faces the environmental problems involving the three waste materials, including wastewater, waste gas and waste residue, and the economic problem of a low mining efficiency [5]. In situ thermal injection oil shale mining can effectively solve the above environmental problems [6], which have attracted the attention of a large number of scholars in China and abroad. Among these scholars, Zhao et al. of the Taiyuan University of Technology proposed the method of in situ steam injection for oil shale production [7]; the core of which entails the efficient injection of hightemperature superheated steam via thermal injection wells into oil shale layers. Then, the oil and gas fluids produced by pyrolysis in the oil shale layers are produced with extraction wells. The evolution of the oil shale permeability at high temperatures can affect the flow of superheated water vapor and pyrolytic oil and gas in oil shale layers and can thus affect the efficiency of in situ pyrolysis. Therefore, studying the evolution law of the oil shale permeability under realtime high-temperature conditions is helpful to determine how to efficiently inject high-temperature steam into oil shale layers.

Under the action of a high temperature, organic matter pyrolysis in oil shale and heterogeneous expansion of 
inorganic minerals generate a large number of pores and fracture structures in oil shale. Pore fracture structures are the flow channels of high-temperature fluids, and new pore fractures at high temperatures can affect the oil shale permeability. Thus, a large number of scholars have performed much research on the change in the pore fracture structure and permeability of oil shale at high temperatures. Kang et al. [8] carried out scanning experiments and permeability tests of oil shale after dry distillation with computed tomography (CT) and triaxial percolation equipment, respectively. A large number of cracks along the parallel bedding direction occurred beyond $400^{\circ} \mathrm{C}$, and the oil shale permeability sharply increased at $400^{\circ} \mathrm{C}$. Tiwari et al. [9] conducted a scanning experiment of the fracture structure in the Green River basin, United States, at high temperatures with CT equipment and obtained the variation law of the permeability with the temperature by analyzing the collected pore fracture structure data. It was found that with increasing temperature, the number of pore fracture structures in oil shale greatly increased, and the permeability increased from 173 to 2199 D. Rabbani et al. [10] calculated the permeability of connected seepage channels in an oil shale digital core at different temperatures with $\mathrm{CT}$ scanning technology and digital core technology. Beyond $400^{\circ} \mathrm{C}$, the oil shale permeability increased sharply to $1 \mathrm{D}$. The change in oil shale permeability was slightly related with the pore size but attained a notable relationship with the pore connectivity. Yang et al. $[11,12]$ studied the change law of the oil shale permeability under the action of high-temperature steam and found that the increase in oil shale permeability was closely related to the change in fracture structures under the action of hightemperature steam. Geng et al. [13] examined the change law of the permeability along the vertical bedding direction of Fushun oil shale after high-temperature treatment. The permeability rapidly increased from 300 to $400^{\circ} \mathrm{C}$, and the increase declined from 400 to $600^{\circ} \mathrm{C}$. Zhao and Kang [14] investigated the permeability change law of Fushun oil shale at a $200 \mathrm{~m}$ buried depth under real-time high-temperature conditions and found that the oil shale permeability continued to increase from 350 to $600^{\circ} \mathrm{C}$.

Most of the above studies on the oil shale permeability were carried out after high-temperature heating. Only the study of Zhao and Kang [14] was executed under real-time high-temperature conditions, but only the oil shale permeability in the Fushun area was studied, while the influence of the ground stress was not considered. However, the mineral composition of Fushun oil shale is obviously different from that of Xinjiang oil shale, of which Liaoning Fushun oil shale is mainly composed of clay mineral kaolinite, while Jimusar oil shale largely consists of quartz and feldspar, with few clay minerals. The variation in the oil shale permeability with the temperature in Xinjiang is likely different due to the difference in mineral composition. However, few scholars have studied the oil shale permeability in the Jimusar area of Xinjiang under real-time high-temperature conditions.

Therefore, this paper employs a real-time hightemperature permeability testing system independently developed by the Taiyuan Institute of Technology to determine the oil shale permeability in the Jimusar area of

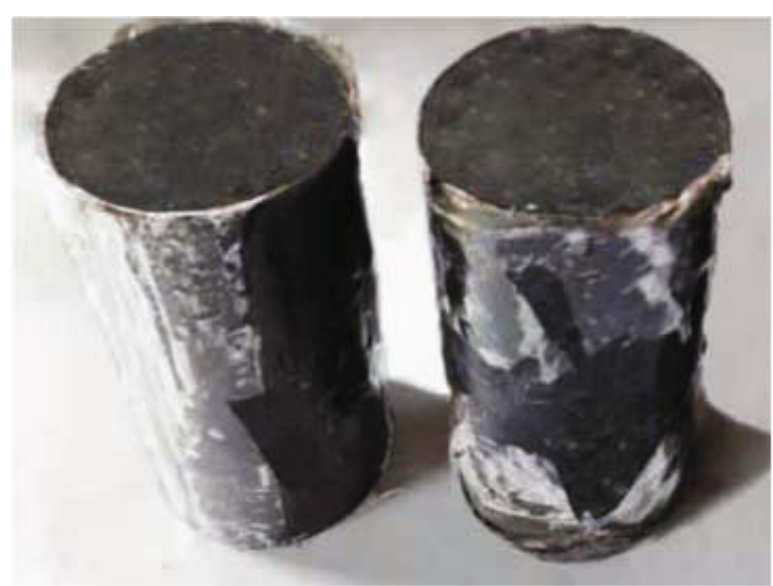

Figure 1: Oil shale specimen.

Xinjiang under real-time high-temperature triaxial stress conditions. The variation in the oil shale permeability at different temperatures, pore pressures, and volumetric stresses was obtained. The evolution law of the oil shale permeability under real-time high-temperature conditions determined in this paper could provide a theoretical reference for the analysis of the flow behavior of heated fluids and pyrolytic oil and gas in oil shale deposits.

\section{Experimental Methods and Steps}

2.1. Specimen Preparation. The test specimens in this paper originate from the Jimusar area in Xinjiang, and all oil shale specimens are sealed and transported to the laboratory for sample processing. Oil shale is cut into $\Phi 50 \mathrm{~mm} \times 100 \mathrm{~mm}$ cylindrical standard specimens with a CNC sand wire cutting machine. As shown in Figure 1, the specimens are cut parallel to the bedding direction. The parallelism and smoothness of the samples meet the standards of the International Society of Rock Mechanics. The color of the sample is brown. The results of industrial and elemental analysis and mineral analysis are listed in Tables 1 and 2, respectively.

\subsection{Test Equipment and Test Process}

(1) Determination of study temperature

According to the TG-DSC curve, the weight loss of oil shale mainly occurs at $400-600^{\circ} \mathrm{C}$, as shown in Figure 2 . Moreover, kerogen in oil shale begins to be pyrolyzed into flowable oil and gas after $400^{\circ} \mathrm{C}$, so the research temperature selected in this paper is $20-600^{\circ} \mathrm{C}$.

\section{(2) Test equipment}

The in situ high-temperature seepage test is carried out with the real-time high-temperature triaxial stress seepage system independently developed by the Taiyuan Institute of Technology, as shown in Figure 3. The test system includes a dynamic loading system, which can apply a pressure up to $32 \mathrm{MPa}$ with an accuracy of $\pm 0.1 \mathrm{MPa}$, a temperature control system, which can generate a temperature up 
TABLE 1: Elemental and industrial analysis.

\begin{tabular}{|c|c|c|c|c|c|c|c|c|c|c|}
\hline \multirow{2}{*}{ Sample } & \multicolumn{6}{|c|}{ Elemental analysis } & \multicolumn{4}{|c|}{ Industrial analysis } \\
\hline & $\mathrm{N} \%$ & $\mathrm{C} \%$ & $\mathrm{H} \%$ & $\mathrm{O} \%$ & $\mathrm{H} / \mathrm{C}$ & $\mathrm{O} / \mathrm{C}$ & Moisture content & Ash content & Volatile matter & Fixed carbon \\
\hline Jimusar, Xinjiang & 1.56 & 8.27 & 2.98 & 9.865 & 2.57 & 0.82 & 5.38 & 79.22 & 11.46 & 3.94 \\
\hline
\end{tabular}

TABle 2: Mineral composition of the oil shale.

\begin{tabular}{lcccccccc}
\hline \multirow{2}{*}{$\begin{array}{l}\text { Sample origin } \\
\text { Quartz }\end{array}$} & Pyrite & Clay minerals & Feldspar & Plagioclase & Calcite & Dolomite & Gypsum \\
\hline Jimusar, Xinjiang & 36.3 & 0.4 & 5.2 & 8.0 & 25.8 & 4.6 & 18.8 & 0.9 \\
\hline
\end{tabular}

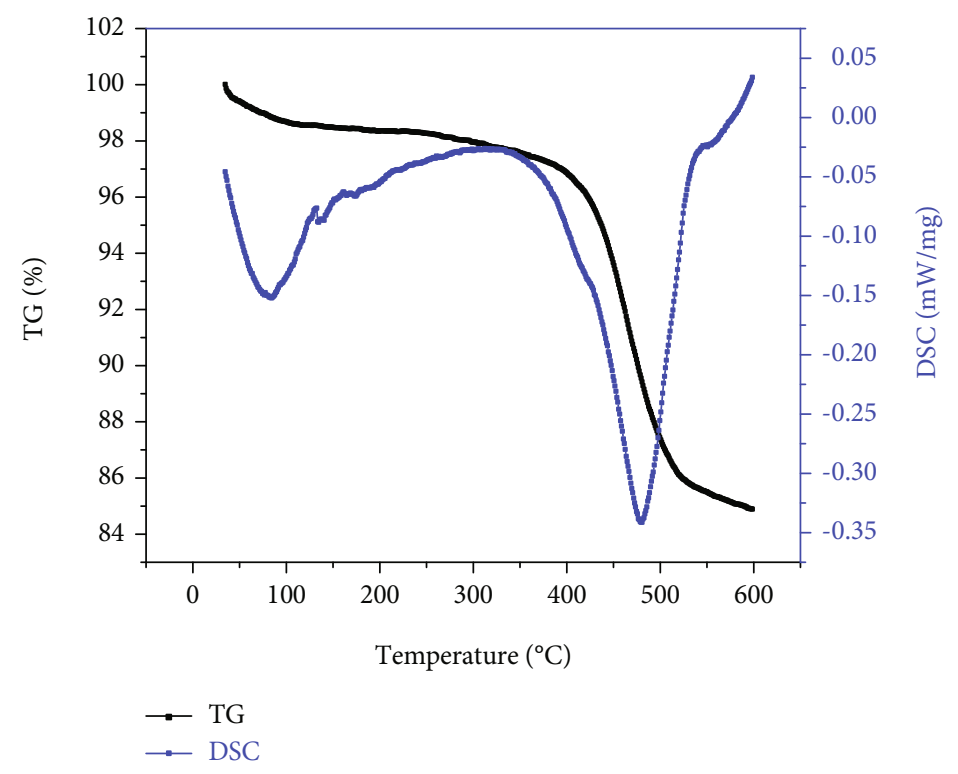

Figure 2: TG-DSC curve.

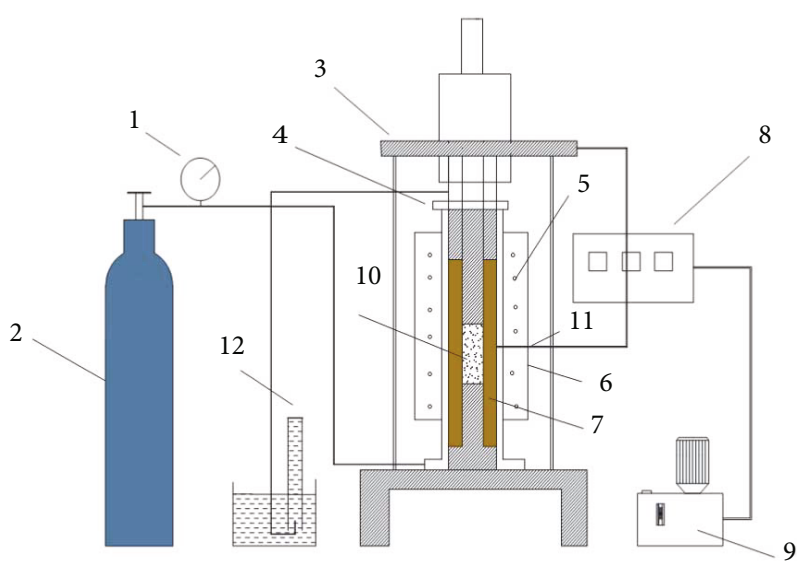

FIGURE 3: Real-time high-temperature triaxial stress seepage penetration testing system. (1) Pressure-reducing valve, (2) cylinder, (3) loading system, (4) triaxial stress chamber, (5) heating sleeve, (6) insulated box, (7) sealing packing, (8) temperature control system, (9) hydraulic system, (10) sample, (11) thermocouple, and (12) air flow measuring equipment.

to $700^{\circ} \mathrm{C}$ at a heating rate of $1^{\circ} \mathrm{C} / \mathrm{min}$, and a confining pressure transmission device, which employs the solid pressure transmission technique to convert axial pressure into lateral
TABle 3: Parameters of the axial, confining, and pore pressures.

\begin{tabular}{lccccccc}
\hline $\begin{array}{l}\text { Buried } \\
\text { depth }\end{array}$ & $\begin{array}{c}\text { Axial } \\
\text { compression } \\
(\mathrm{MPa}), \sigma_{x}\end{array}$ & $\begin{array}{c}\text { Confining } \\
\text { pressure } \\
(\mathrm{MPa}), \sigma_{y}\end{array}$ & $\begin{array}{c}\text { Volumetric } \\
\text { stress }(\mathrm{MPa}), \\
\sigma_{x}+2 \sigma_{y}\end{array}$ & $\begin{array}{c}\text { Pore } \\
\text { pressure } \\
(\mathrm{MPa}), P_{m}\end{array}$ \\
\hline $200 \mathrm{~m}$ & 5 & 6 & 17 & 1 & 2 & 3 & \\
$400 \mathrm{~m}$ & 10 & 12 & 34 & 1 & 2 & 3 & 4 \\
\hline
\end{tabular}

pressure and further applies a confining pressure to the specimen.

\section{(3) Test process}

The in situ high-temperature permeability testing process is as follows: (1) different axial and confining pressures are loaded according to the buried depth of oil shale in the Jimusar area of Xinjiang (Table 3). (2) The permeability is tested under different pore pressures (Table 3 ) at room temperature, nitrogen is permeated under the different pressures, each pore pressure test interval lasts $20 \mathrm{~min}$ to prevent the influence of the last pore pressure interval on the test results, and the lower flow rate $Q$ is recorded under each pore pressure. (3) The heating system is activated, the specimen is then heated to the preset temperature $\left(100^{\circ} \mathrm{C}\right.$, 


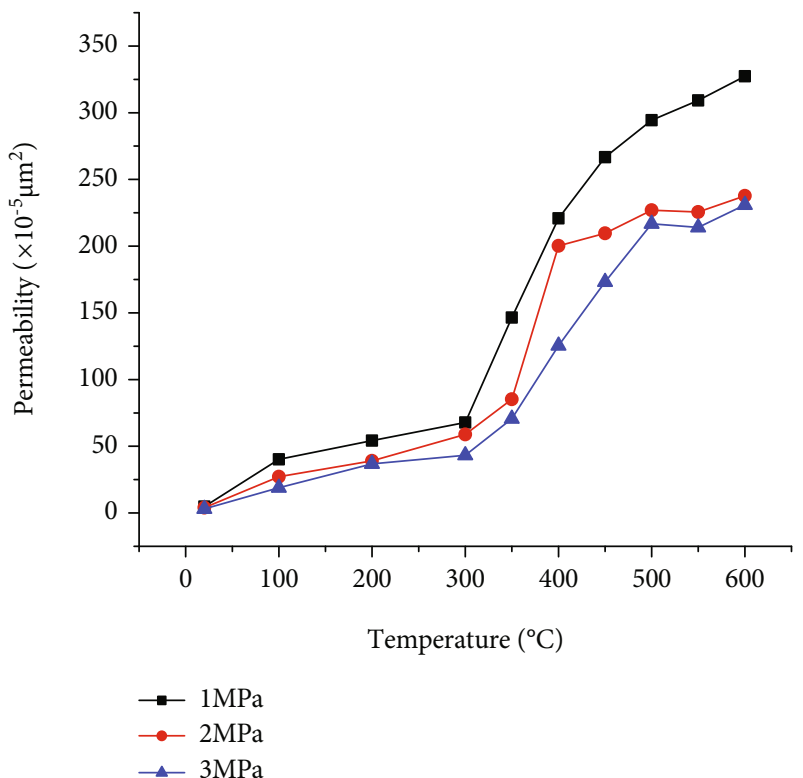

(a) $\Theta=17 \mathrm{MPa}$

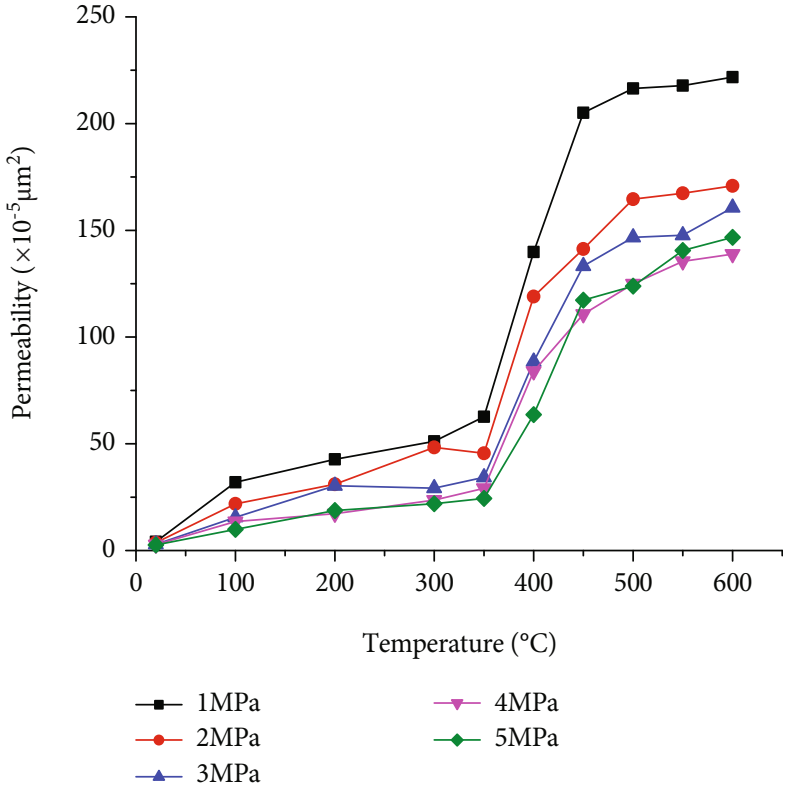

(b) $\Theta=34 \mathrm{MPa}$

FIGURE 4: Variation in the permeability with the temperature.

$200^{\circ} \mathrm{C}, 300^{\circ} \mathrm{C}, 350^{\circ} \mathrm{C}, 400^{\circ} \mathrm{C}, 450^{\circ} \mathrm{C}, 500^{\circ} \mathrm{C}, 550^{\circ} \mathrm{C}$, or $600^{\circ} \mathrm{C}$ ) at a heating rate of $1^{\circ} \mathrm{C} / \mathrm{min}$, and finally, the oil shale permeability is determined under the different pore pressures, as indicated in Table 3, with the same method as that in step 2.

The permeating medium used in this paper is $\mathrm{N}_{2}$, which conforms to Darcy's law, so Equation (1) is applied to calculate the permeability.

$$
k=\frac{2 Q P_{\text {down }} L \mu}{\left(P_{\text {up }}^{2}-P_{\text {down }}^{2}\right) A},
$$

where $k$ is the permeability, $\mathrm{m}^{2} ; Q$ is the flow rate, $\mathrm{m}^{3} / \mathrm{s} ; P 0$ is the atmospheric pressure, at $0.1 \mathrm{MPa}$; $L$ is the specimen length, $\mathrm{m} ; \mu$ is the gas dynamic viscosity, MPa.s; $P_{\text {up }}$ is the inlet pressure, $\mathrm{MPa}$; $P_{\text {down }}$ is the outlet pressure, $\mathrm{MPa}$; and $A$ is the cross-sectional area of the specimen, $\mathrm{m}^{2}$.

\section{Test Results}

3.1. Permeability Changes with the Temperature. Figure 4 shows the variation of oil shale permeability with the temperature under the different volumetric stresses. The permeability is very low at room temperature and reaches $3.01 \times 10^{-5} \mu \mathrm{m}^{2}$ under a pressure of $2 \mathrm{MPa}$. The permeability gradually increases with increasing temperature. Although different stresses are applied to the oil shale specimen, the permeability exhibits a similar transformation pattern under the different volumetric stresses. Therefore, according to Figure 3, the variation trend of the permeability with the temperature is divided into three stages, and these three stages are analyzed with the permeability data obtained under a volumetric stress of $17 \mathrm{MPa}$ and a pore pressure of $2 \mathrm{MPa}$.
From 20 to $350^{\circ} \mathrm{C}$, the permeability increases slowly. At $100^{\circ} \mathrm{C}$, the permeability increases from $4.7 \times 10^{-5}$ to $18.9 \times$ $10^{-5} \mu \mathrm{m}^{2}$, which is 6.3 times higher than that at $100^{\circ} \mathrm{C}$. This occurs because the loss of free water at $100^{\circ} \mathrm{C}$ results in small cracks [15] parallel to the bedding direction in the oil shale specimen, causing an increase in permeability. Wang et al. studied the thermal fracture evolution law of oil shale under high temperature and found that there are connected fractures in the direction parallel to bedding at $100^{\circ} \mathrm{C}$, as shown in Figure 5 [16], which verified the increase of oil shale permeability at $100^{\circ} \mathrm{C}$. As the temperature is continuously increased, the oil shale permeability continues to slowly increase, which is attributed to the loss of the volatile oil shale fraction at high temperatures.

At 350 and $500^{\circ} \mathrm{C}$, the permeability increases rapidly. The oil shale permeability increases sharply at $400^{\circ} \mathrm{C}$, which is 23 times higher than that at room temperature. This occurs due to the initiation of kerogen pyrolysis in the oil shale specimen at $400^{\circ} \mathrm{C}[9,10]$, resulting in the connection of a large number of pores and cracks in the oil shale specimen, which leads to a sharp increase in the oil shale permeability. It can be seen from Figure 5 that a large number of oil shale fractures are developed after $400^{\circ} \mathrm{C}$, which also verifies that the permeability of oil shale will rise rapidly after $400^{\circ} \mathrm{C}$. Therefore, $400^{\circ} \mathrm{C}$ can be defined as the threshold temperature in terms of the evolution of permeability of Jimusar oil shale. With increasing temperature to $500^{\circ} \mathrm{C}$, kerogen pyrolysis continues, and the permeability continuously increases.

At 500 and $600^{\circ} \mathrm{C}$, the permeability stabilizes and then increases, respectively. Kerogen pyrolysis in the oil shale specimen is basically completed beyond $500^{\circ} \mathrm{C}$, and the permeability increase rate of the oil shale specimen begins to stabilize, but the permeability still increases because feldspar 


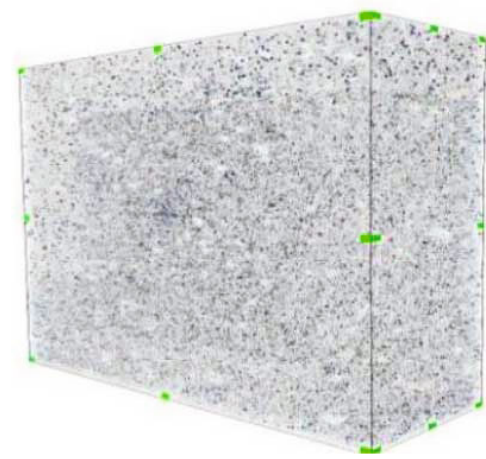

(a) $20^{\circ} \mathrm{C}$

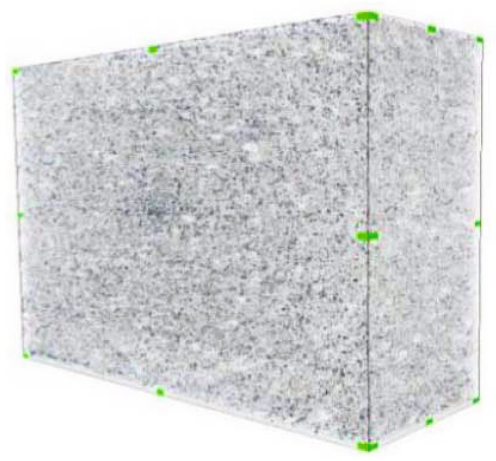

(d) $350^{\circ} \mathrm{C}$

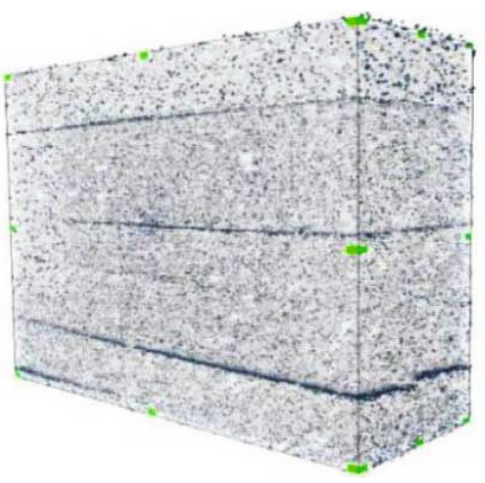

(g) $500^{\circ} \mathrm{C}$

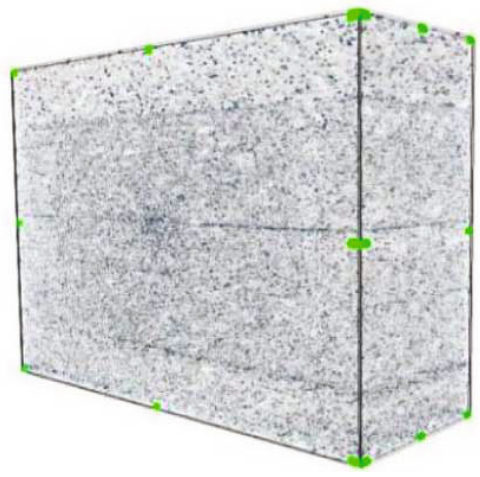

(b) $100^{\circ} \mathrm{C}$

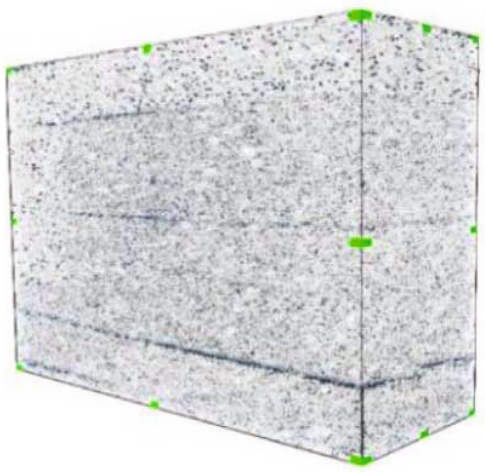

(e) $400^{\circ} \mathrm{C}$

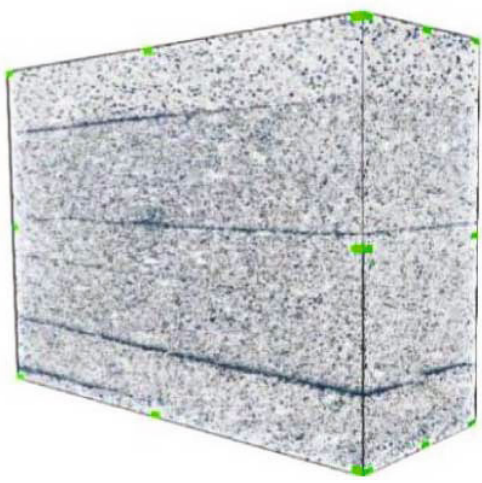

(h) $550^{\circ} \mathrm{C}$

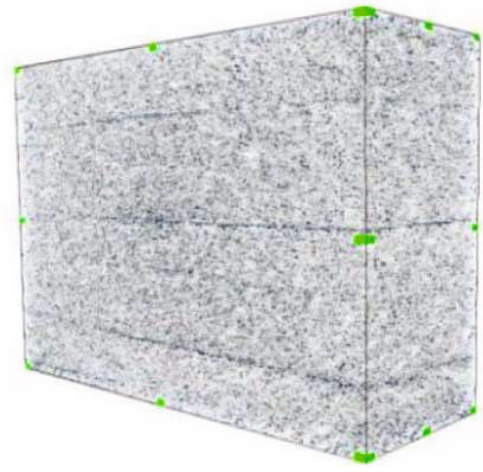

(c) $300^{\circ} \mathrm{C}$

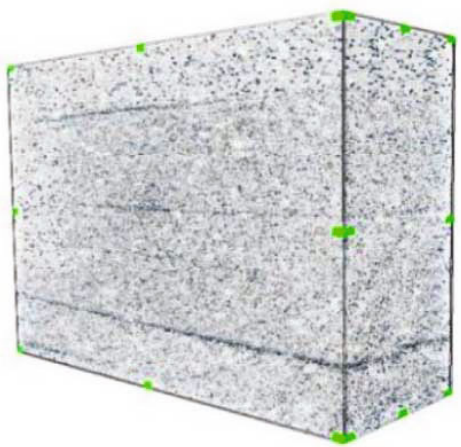

(f) $450^{\circ} \mathrm{C}$

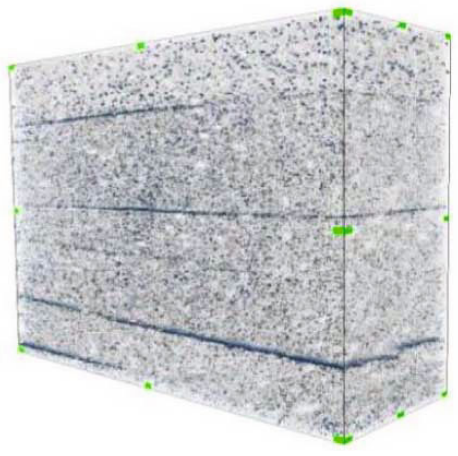

(i) $600^{\circ} \mathrm{C}$

FIgURE 5: Anisotropic thermal cracking of oil shale [16].

in the oil shale specimen begins to decompose at $500^{\circ} \mathrm{C}$, resulting in an increase in the permeability. It can also be seen from Figure 5 that fractures will continue to increase after $500^{\circ} \mathrm{C}$, so the permeability at $500^{\circ} \mathrm{C}$ continues to increase compared with that at $400^{\circ} \mathrm{C}$. At $600^{\circ} \mathrm{C}$, the fracture growth rate slows down, so the permeability will not increase at $600^{\circ} \mathrm{C}$. In addition, it can be found that the permeability rise rate at $600^{\circ} \mathrm{C}$ is smaller under $34 \mathrm{MPa}$ volumetric stress, because the thermal fracture of oil shale will be closed under high stress. Then, under the combined action of thermal stress and high ground stress, the permeability of oil shale will no longer increase.

3.2. Permeability Changes with the Pore Pressure. The variation trend of the oil shale permeability with the pore pres- sure is shown in Figure 6. Regardless of the volumetric stress or temperature, the oil shale permeability decreases with increasing pore pressure, but the decrease in permeability differs between the different volumetric stresses.

When the volumetric stress is $17 \mathrm{MPa}$, the permeability decreases greatly when the pore pressure ranges from 1 to approximately $2 \mathrm{MPa}$. This occurs because the Klinkenberg effect is notable at the low pore pressure stage $[17,18]$, which leads to the maximum oil shale permeability under $1 \mathrm{MPa}$. With increasing pore pressure to $2 \mathrm{MPa}$, the effective stress on the oil shale specimen decreases obviously, which leads to a decrease in the permeability, but the Klinkenberg effect still plays a leading role.

Under a volumetric stress of $34 \mathrm{MPa}$, the permeability greatly decreases when the pore pressure ranges from 1 to 


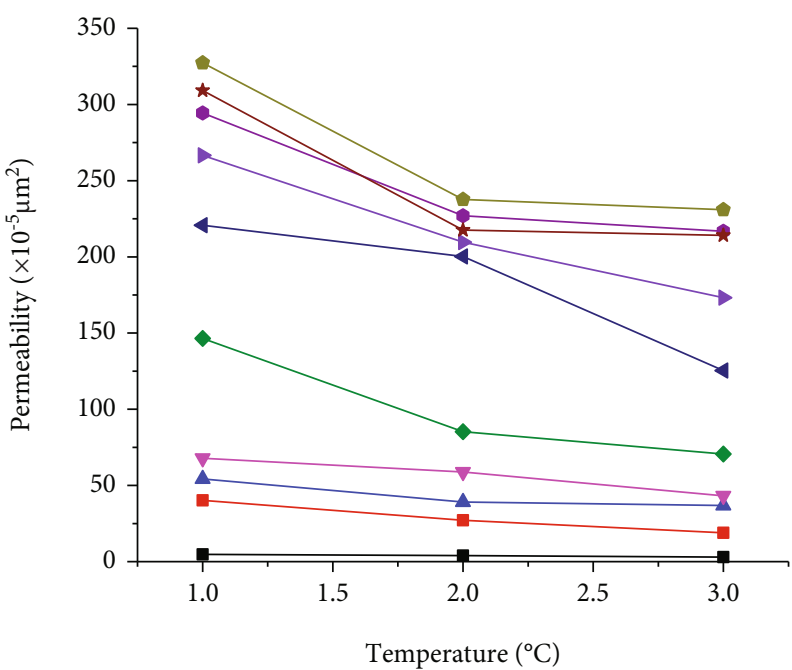

(a) $\Theta=17 \mathrm{MPa}$

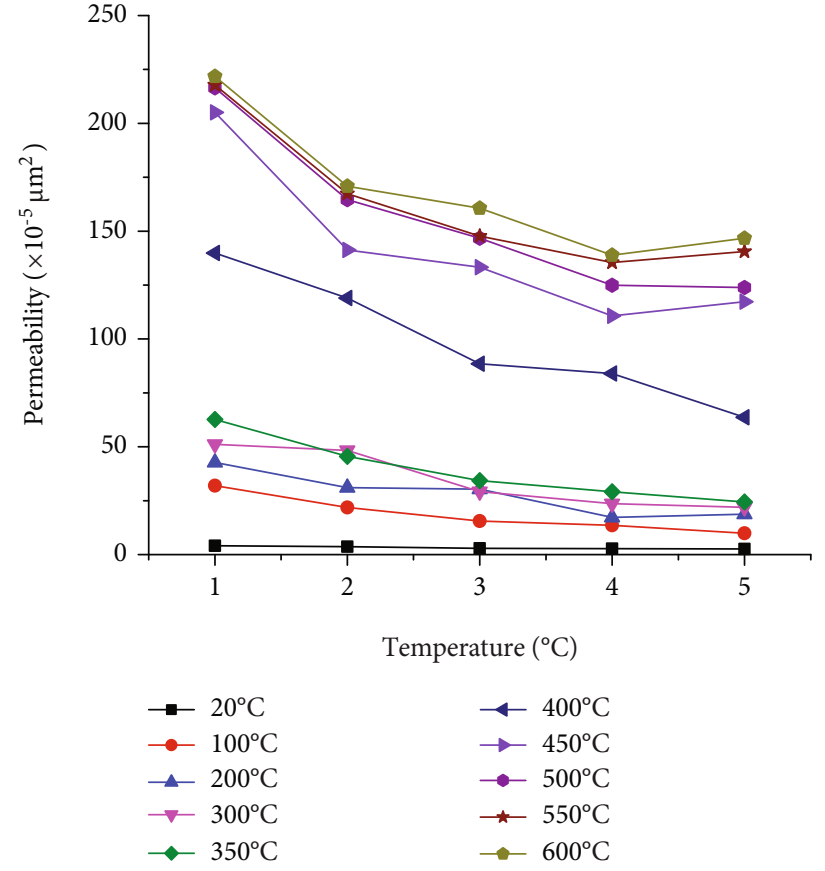

(b) $\Theta=34 \mathrm{MPa}$

FIgURE 6: Effect of the pore pressure on the permeability.

approximately $3 \mathrm{MPa}$, which is still attributable to the obvious Klinkenberg effect at lower pore pressures, which leads to a higher oil shale permeability under lower pore pressures than that under higher pore pressures. However, when the volumetric stress reaches $34 \mathrm{MPa}$, the increase in pore pressure to $3 \mathrm{MPa}$ is not enough to notably reduce the effective stress, overcome the Klinkenberg effect, and constrain the decrease in oil shale permeability.

3.3. Variation in the Permeability with the Volumetric Stress. The permeability under pore pressures of 2 and $3 \mathrm{MPa}$ are chosen as an example to study the influence of the cumulative stress on the oil shale specimen at the different temperatures on the change in permeability. Permeability histograms under volumetric stresses of 17 and $34 \mathrm{MPa}$ at the different temperatures are drawn based on the test data, as shown in Figure 7.

At the same temperature, the oil shale permeability decreases with increasing volumetric stress. However, the oil shale permeability decrease amount varies between the different temperatures. At $20^{\circ} \mathrm{C}$, the pore pressure decreases by $8 \%$ and $3 \%$ under 2 and $3 \mathrm{MPa}$, respectively. As the temperature continues to rise, the permeability increasingly decreases with increasing volumetric stress, reaching $46 \%$ and $51 \%$, respectively, at $350^{\circ} \mathrm{C}$, because solid organic matter is first converted into fluid asphaltene [19] at $350^{\circ} \mathrm{C}$. Oil shale is more likely to deform when the volumetric stress is higher, thus blocking seepage channels. At $400^{\circ} \mathrm{C}$, a high degree of organic matter pyrolysis occurs in the oil shale specimen, resulting in more pyrolysis-induced pore fracture structures. Under high volumetric stresses, the pore fracture structures are closed, resulting in a larger decrease of $40 \%$ and 39\%, respectively. The oil shale strength is higher at lower temperatures, and the permeability decreases little with increasing volumetric stress. With increasing temperature, the pore fracture structures produced by oil shale softening and pyrolysis causes oil shale to deform more easily under high volumetric stresses [20], and the internal pore fissures in the oil shale specimen more readily collapse, which leads to a decrease in permeability with increasing volumetric stress, which is consistent with the variation in the Fushun oil shale permeability with the volumetric stress obtained by Geng [13].

\section{Discussion}

4.1. Mechanism of Permeability Evolution with the Temperature. In Section 2.1, it was mentioned that the variation in the oil shale permeability with the temperature is closely related to the decomposition of organic matter and inorganic minerals in oil shale. In this section, a weight loss curve of the oil shale specimen in the temperature range from $20^{\circ} \mathrm{C}$ to $600^{\circ} \mathrm{C}$ is obtained in thermogravimetric experiments. Figure 8 shows the curve of the weight loss and permeability of the oil shale specimen with the temperature. The ratio of the oil shale permeability $(K)$ at the different temperatures to the oil shale permeability $\left(K_{0}\right)$ at room temperature under a pressure of $2 \mathrm{MPa}$ is indicated on the left axis, for theta $=17 \mathrm{MPa}$. The diagram reveals that the weight loss curve exhibits the first decrease point at $100^{\circ} \mathrm{C}$, where the oil shale specimen begins to lose its internal free water, resulting in the first increase in the oil shale permeability. The main stage of oil shale weight loss ranges from 400 to $500^{\circ} \mathrm{C}$, which further suggests that a large amount of kerogen 


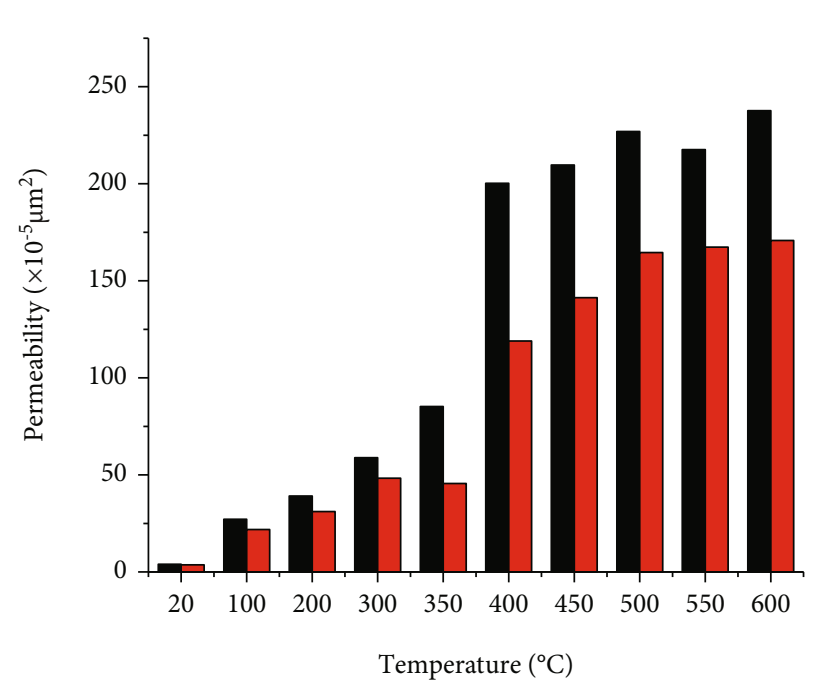

(a) $P_{m}=2 \mathrm{MPa}$

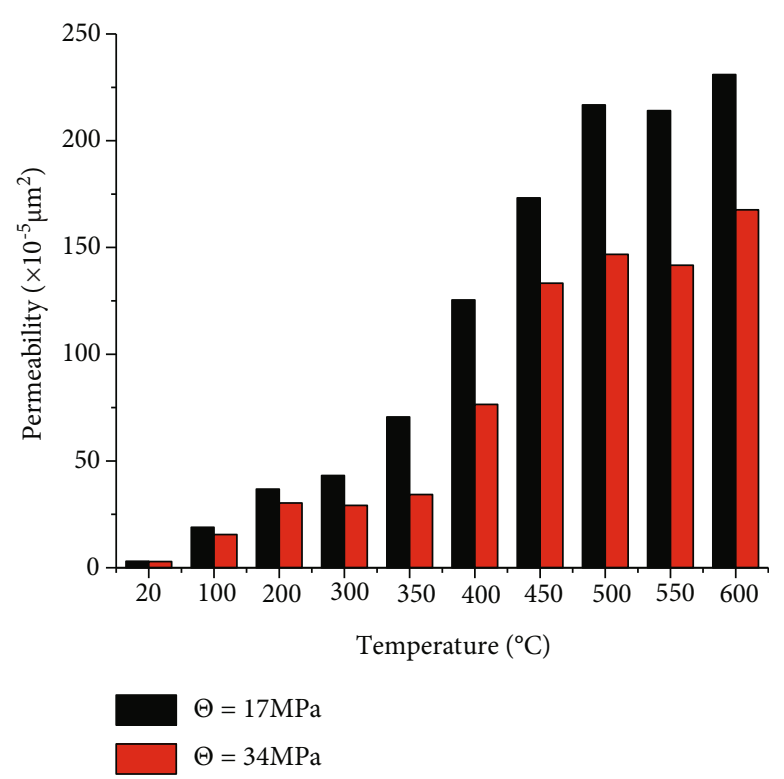

(b) $P_{m}=3 \mathrm{MPa}$

FIGURE 7: Effect of the volumetric stress on the permeability.

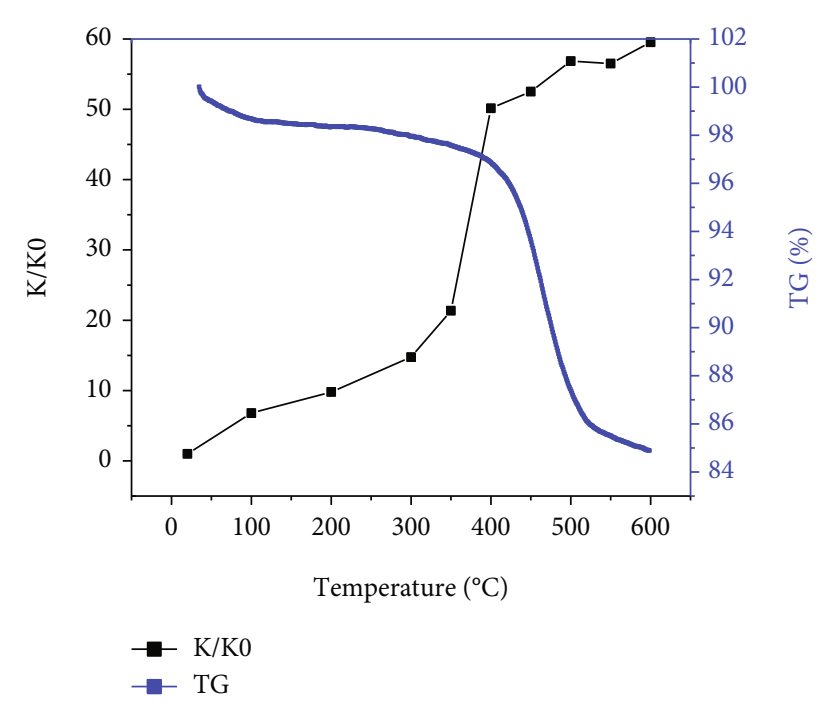

FIGURE 8: Variation in the weight loss rate with the temperature.

in the oil shale specimen is pyrolyzed at this temperature, resulting in a sharp increase in the oil shale permeability at this temperature. When the temperature is higher than $500^{\circ} \mathrm{C}$, the weight loss rate begins to decrease, which is the stage of growth rate deceleration of the oil shale permeability.

The release of gas products indicates that there are connected seepage channels in the oil shale specimen, which causes these products to be released. Therefore, the variation in gas products due to kerogen pyrolysis with the temperature can effectively explain the variation in the permeability with the temperature. As can be seen in Figure 9, only a small amount of gas products is produced from 100 to $350^{\circ} \mathrm{C}$, mainly free water and volatile matter. When the tem- perature rises to $400^{\circ} \mathrm{C}$, a large number of gas products is produced, which indicates that a large number of connected pores and fracture channels are generated in the oil shale specimen so that the gas products can be released from the matrix. This temperature point indicates the threshold temperature of oil shale permeability variation with the temperature. Beyond $500^{\circ} \mathrm{C}$, the gas products begin to decrease, which indicates that the kerogen pyrolysis process in the oil shale specimen is basically completed, while the connected pores no longer increase, which is also the stage of slow permeability growth.

\subsection{Comparative Analysis of the Evolution of the Oil Shale} Permeability with the Temperature in the Different Areas. As the evolution of the oil shale permeability with the temperature plays a very important role in the in situ exploitation process of oil shale, predecessors have assessed the oil shale permeability in the Fushun area. Wang et al. [16] and Zhao and Kang [14] both measured the oil shale permeability at a depth of $200 \mathrm{~m}$ and obtained the change rules of the oil shale permeability with the temperature. The variation in permeability with the temperature under a pore pressure of $2 \mathrm{MPa}$ obtained by predecessors and that determined in this experiment are compared and analyzed in the same diagram, as shown in Figure 10.

Figure 8 shows that the variation trend of the oil shale permeability with the temperature is similar between the Jimusar area of Xinjiang and the Fushun area of Liaoning Province. However, the oil shale permeability in the Jimusar area of Xinjiang is obviously higher than that in the Fushun area of Liaoning Province. This occurs because the clay mineral content in the oil shale of the Fushun area reaches 42.6 [21] at room temperature, while the clay mineral content in the oil shale of the Jimusar area reaches only 5\%. As a result, the oil shale in the Fushun area of Liaoning Province is 


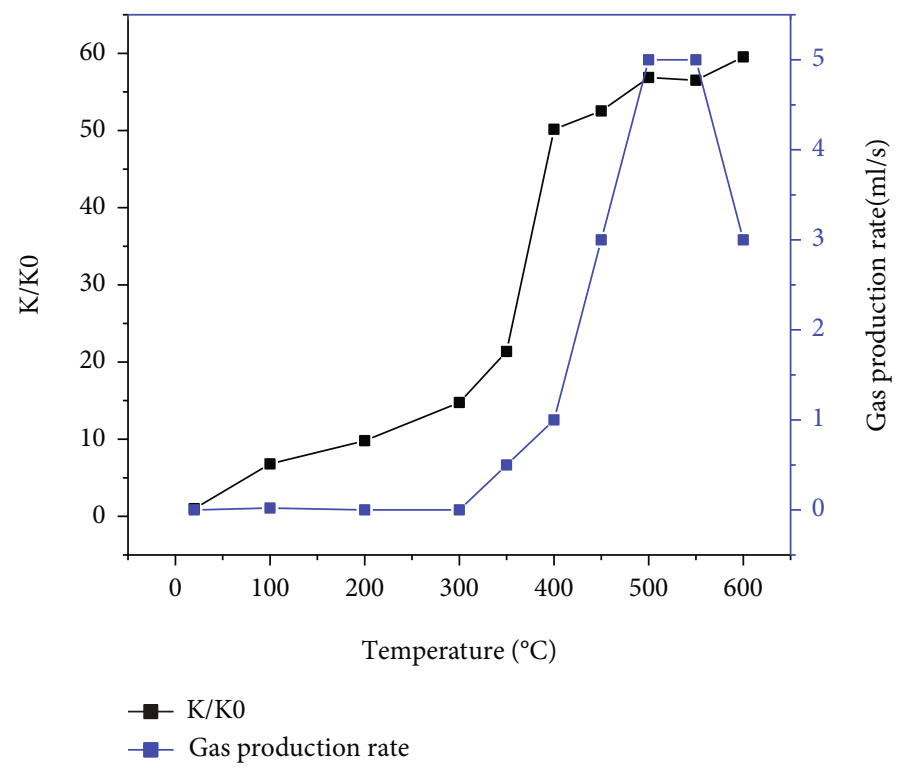

FIGURE 9: Variation in the production quantity with the temperature.

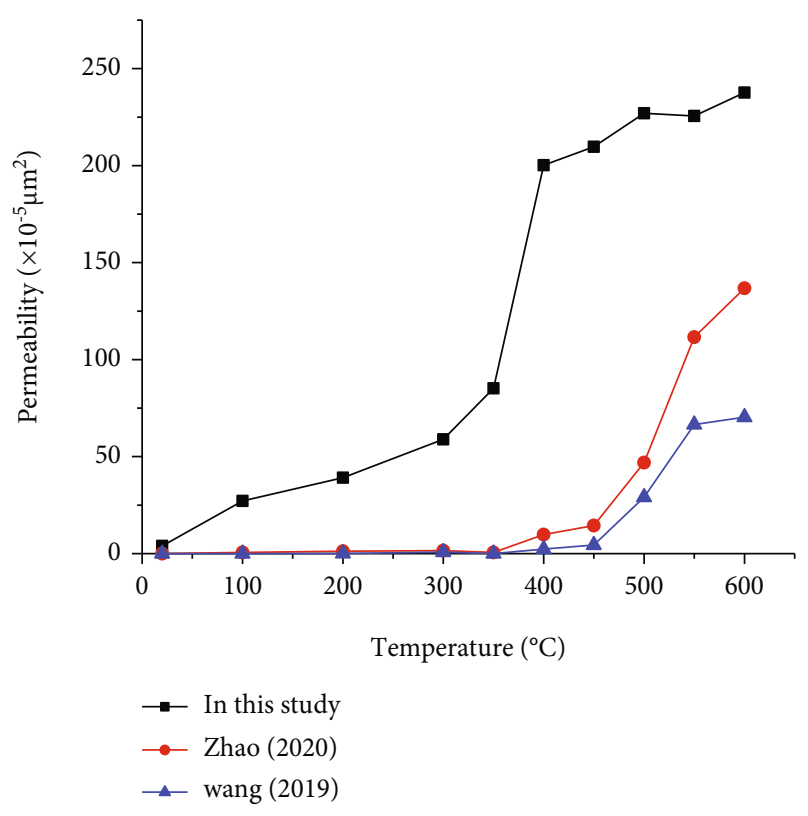

Figure 10: Comparison of the oil shale permeability between the different areas.

denser at room temperature, and the permeability is lower. With increasing temperature, the oil shale of the Jimusar area is subject to not only internal kerogen pyrolysis but also heterogeneous expansion deformation of minerals such as quartz (36.3\%) and plagioclase (25.8\%). As a result, the oil shale permeability in the Jimusar area of Xinjiang is relatively high.

4.3. Practical Application. In the process of in situ heating shale for oil production, high-temperature steam shall be injected into the oil shale seam through the injection well, as shown in Figure 11 [22]. In the process of injection, the permeability evolution of oil shale will not only affect the injection efficiency of high-temperature steam but also affect the migration speed of oil and gas from oil shale to pumping wells after pyrolysis. In this paper, the real-time seepage experiment under high-temperature triaxial stress can truly reflect the seepage evolution law of oil shale under the combined action of in situ stress and temperature. It is found that the permeability of oil shale increases obviously at $400^{\circ} \mathrm{C}$, that is, the injection temperature should be higher than $400^{\circ} \mathrm{C}$ in the process of injecting high-temperature steam. The permeability of oil shale decreases with the increase of in situ stress. The increase of in situ stress weakens the permeability, but the permeability of oil shale still increases at high temperature, indicating that the temperature still strengthens the permeability of oil shale under high ground stress. Therefore, the experimental results of this paper can provide data and theoretical support for in situ thermal injection and shale production.

\section{Conclusion}

In this paper, a real-time high-temperature triaxial permeability testing system independently developed by the Taiyuan Institute of Technology is employed to simulate the in situ high-temperature oil shale environment, and the variation in the oil shale permeability with the temperature in the Jimusar area of Xinjiang under real-time high-temperature triaxial stress conditions is obtained. The conclusions are as follows:

(1) The variation in the oil shale permeability with the temperature can be divided into three stages: the slow growth stage ranges from 20 to $350^{\circ} \mathrm{C}$. This stage of the permeability change process is mainly caused by the loss of free water and volatiles. The rapid growth stage occurs from 350 to $500^{\circ} \mathrm{C}$. The 


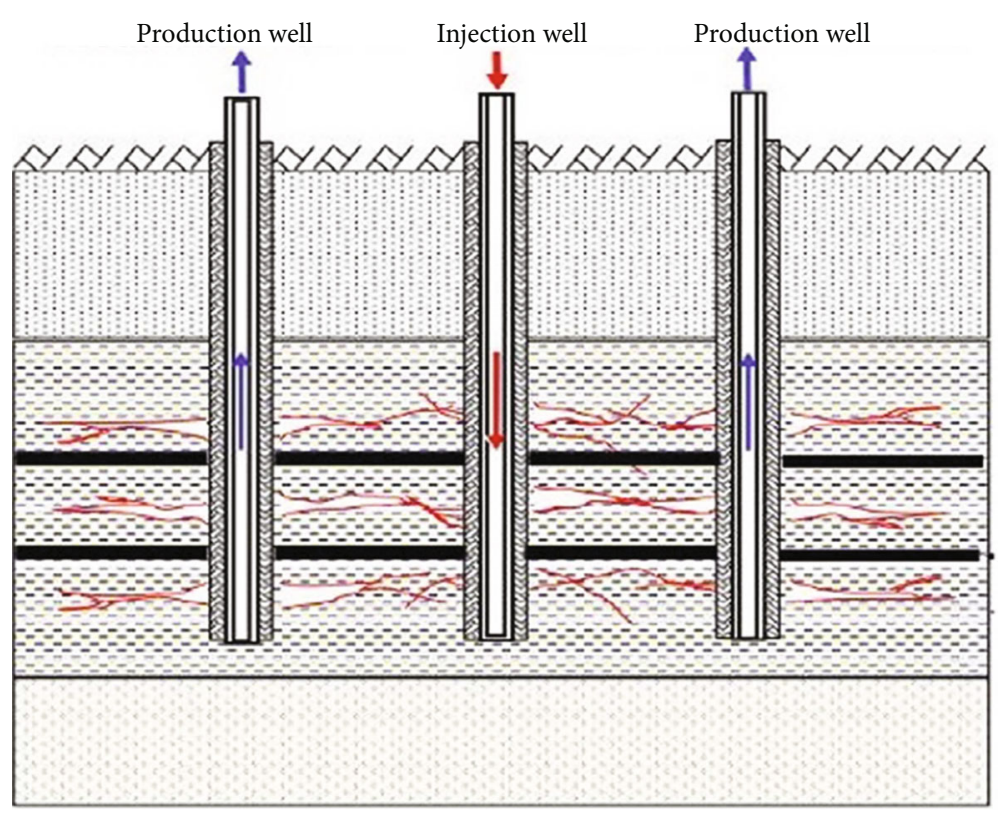

(a)

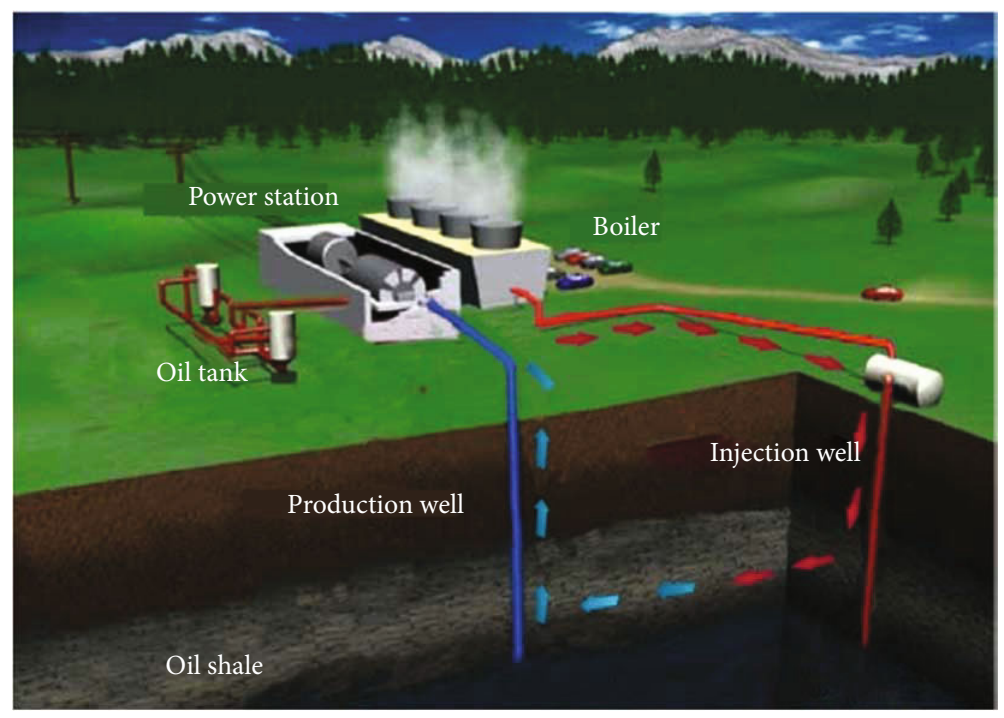

(b)

FIGURE 11: The oil shale in situ convection technology using injected superheated steam (MTI): (a) hydraulic fracturing and (b) schematic of the MTI system [22].

growth at this stage is mainly caused by the pyrolysis of oil shale kerogen, and $400^{\circ} \mathrm{C}$ is the threshold temperature. From 500 to $600^{\circ} \mathrm{C}$, the growth process decelerates

(2) Under the same volumetric stress, with increasing pore pressure, the oil shale permeability first rapidly decreases and then slowly decreases. However, the change trend differs between the different volumetric stresses. Under the $17 \mathrm{MPa}$ volumetric stress, the permeability decreases rapidly and then slowly from 1 to approximately $2 \mathrm{MPa}$. Under the $34 \mathrm{MPa}$ volumetric stress, when the pore pressure ranges from 1 to approximately $3 \mathrm{MPa}$, the permeability first rapidly decreases and then slowly decreases
(3) At the same temperature, the oil shale permeability continuously decreases with increasing volumetric stress. However, the decrease amount varies between the different temperatures, the decrease amount is the smallest at room temperature, and the permeability decrease amount increases gradually with increasing temperature, which is attributed to oil shale softening and pyrolysis of the internal organic matter, which results in easier oil shale deformation under the action of external stress, resulting in pore fissure closure

(4) The oil shale permeability in the Jimusar area is obviously higher than that in the Fushun area because the oil shale in the Jimusar area contains 
higher contents of quartz and feldspar and fewer clay minerals, which makes it easier to produce more thermal cracks at high temperatures to form more seepage channels

\section{Data Availability}

All data used to support the study is included within the article.

\section{Conflicts of Interest}

The authors declare that there is no conflict of interest regarding the publication of this paper.

\section{Acknowledgments}

The authors appreciate the financial support from the foundation of Shanxi Institute of Energy (ZZ-2018003 and 2018001).

\section{References}

[1] Z. J. Liu, Q. S. Dong, S. Q. Ye et al., "Current situation of oil shale resources in China," Journal of Jilin University (Earth Science Edition), vol. 36, no. 6, pp. 869-879, 2006.

[2] Z. Liu, Q. Meng, Q. Dong et al., "Characteristics and resource potential of oil shale in China," Oil Shale, vol. 34, no. 1, pp. 1541, 2017

[3] D. Li, D. Tang, and Y. Yang, "Research, development and utilization of oil shale resources," Petroleum Exploration and Development, vol. 33, no. 6, pp. 657-661, 2006.

[4] J. Wang, L. Feng, M. Steve, X. Tang, T. E. Gail, and H. Mikael, "China's unconventional oil: a review of its resources and outlook for long- term production," Energy, vol. 82, pp. 31-42, 2015.

[5] Z. Li and X. Wang, "Ecological environment problems in the development and utilization of oil shale resources," Petrochemical Environmental Protection, vol. 3, pp. 8-12, 1991.

[6] Y. Tang, Y. Bai, and W. Wu, "New energy in Northwest Chinatypical characteristics of oil shale and several issues in its development and utilization," China Geology, vol. 38, no. 3, pp. 731-741, 2011.

[7] Y. S. Zhao, Z. C. Feng, and D. Yang, "The method for mining oil \& gas from oil shale by convection heating," China Patent, CN200510012473.4, 5, 2010.

[8] Z. Kang, D. Yang, Y. Zhao, and Y. Hu, "Thermal cracking and corresponding permeability of Fushun Oil Shale," Oil Shale, vol. 28, no. 2, pp. 273-283, 2011.

[9] P. Tiwari, M. Deo, C. Lin, and J. D. Miller, "Characterization of oil shale pore structure before and after pyrolysis by using Xray micro CT," Fuel, vol. 107, pp. 547-554, 2013.

[10] A. Rabbani, T. G. Baychev, S. Ayatollahi, and A. P. Jivkov, "Evolution of pore-scale morphology of oil shale during pyrolysis: a quantitative analysis," Transport in Porous Media, vol. 119, no. 1, pp. 143-162, 2017.

[11] D. Yang, J. Xue, Z. Kang, and Z. H. Liu, "Dry distillation and seepage experiments of Fushun oil shale," Journal of Xi'an Petrol University, vol. 22, no. 2, pp. 23-25, 2007.
[12] Z. Liu, D. Yang, J. Xue, and Y. S. Zhao, "Experimental study on the Seepage Lawof Distilied Oil Shale," Journal of Taiyuan University, vol. 37, no. 4, pp. 414-416, 2006.

[13] Y. Geng, "Experimental study on physical and mechanical properties of oil shale underground in-situ fracturing and pyrolysis," Journal of Taiyuan University, 2018.

[14] J. Zhao and Z. Kang, "Permeability of oil shale under in situ conditions: Fushun Oil Shale (China) experimental case study," Natural Resources Research, vol. 30, no. 1, pp. 753763, 2021.

[15] F. Bai, Y. Sun, Y. Liu, and M. Guo, "Evaluation of the porous structure of Huadian oil shale during pyrolysis using multiple approaches," Fuel, vol. 187, pp. 1-8, 2017.

[16] G. Wang, D. Yang, Y. Zhao, Z. Kang, J. Zhao, and X. Huang, "Experimental investigation on anisotropic permeability and its relationship with anisotropic thermal cracking of oil shale under high temperature and triaxial stress," Applied Thermal Engineering, vol. 146, pp. 718-725, 2019.

[17] M. Firouzi, K. Alnoaimi, A. Kovscek, and J. Wilcox, "Klinkenberg effect on predicting and measuring helium permeability in gas shales," International Journal of Coal Geology, vol. 123, pp. 62-68, 2014.

[18] T. Chen, X. Feng, and Z. Pan, "Experimental study of swelling of organic rich shale in methane," International Journal of Coal Geology, vol. 150-151, pp. 64-73, 2015.

[19] T. Saif, Q. Lin, K. Singh, B. Bijeljic, and M. J. Blunt, "Dynamic imaging of oil shale pyrolysis using synchrotron X-ray microtomography," Geophysical Research Letters, vol. 43, no. 13, pp. 6799-6807, 2016.

[20] E. Eseme, R. Littke, and B. M. Krooss, "Factors controlling the thermo-mechanical deformation of oil shales: Implications for compaction of mudstones and exploitation," Marine and Petroleum Geology, vol. 23, no. 7, pp. 715-734, 2006.

[21] Z. Liu, "Study on the evolution law of pore structure and permeability characteristics of oil shale under temperature," Journal of Taiyuan University, 2018.

[22] Z. Kang, Y. Zhao, and D. Yang, "Review of oil shale in-situ conversion technology," Journal of Applied Energy, vol. 269, article 115121, 2020. 